\title{
Immediate and Reflective Senses
}

\author{
Angela Mendelovici \\ Penultimate draft*
}

\begin{abstract}
This paper argues that there are two distinct kinds of senses, immediate senses and reflective senses. Immediate senses are what we are immediately aware of when we are in an intentional mental state, while reflective senses are what we understand of an intentional mental state's (putative) referent upon reflection. I suggest an account of immediate and reflective senses that is based on the phenomenal intentionality theory, a theory of intentionality in terms of phenomenal consciousness. My focus is on the immediate and reflective senses of thoughts and the concepts they involve, but it also applies to other mental instances of intentionality.
\end{abstract}

\section{Introduction}

It is sometimes held that thoughts and other intentional mental states have two distinct semantic features: sense and reference, where reference is a matter of picking out or targeting specific items and sense is a matter of how subjects conceive of these items. While I think this is more or less the right picture, I want to suggest that we need to make a further distinction between two different

*Forthcoming in May 2019 in Dena Shottenkirk, Manuel Curado, Steven Gouveia (eds.). Perception, Cognition, and Aesthetics. Routledge. 
kinds of senses: immediate senses, which are what we are immediately aware of in having an intentional mental state, and reflective senses, which are what we understand of an intentional mental state's (putative) referent upon reflection. This paper has two aims: The first is to argue that thoughts and other mental states have immediate and reflective senses, and that, in many cases, they are distinct. The second is to suggest that the phenomenal intentionality theory, a theory of intentionality based on phenomenal consciousness, provides the best account of immediate and reflective senses. ${ }^{1}$

\section{Two Kinds of Senses}

This paper is concerned with the semantic features of mental states. Although my claims are meant to apply to various kinds of mental states, my main arguments focus on the case of thoughts, the mental states we are in when we do what we commonly call "thinking." Thoughts include occurrent states such as judgments and occurrent desires (desires we are currently entertaining), but not perceptual experiences or standing states, such as beliefs we are not currently entertaining. Thoughts seem to "say" or represent something, target things in the world, and be assessable for truth and accuracy. For example, a thought might represent that Eleni is intelligent, target Eleni herself, and be true just in case Eleni is in fact intelligent.

In discussing semantic features, it is useful to assume a distinction between semantic features and the items that have them, which are the vehicles of representation, or representations, for short. As I am using the terms, mental states such as thoughts, beliefs, desires, and many perceptual states are examples of representations. It is also useful to assume that most thoughts are complex in

\footnotetext{
${ }^{1}$ Many of the ideas in this paper are discussed in greater detail in chapter 7 of Mendelovici 2018
} 
that they are composed of other representations, which I will call concepts. ${ }^{2}$ For example, a thought that cats have tails might be partly composed of the concept CAT, which might also be involved in other thoughts, such as the thought that Mitten is a cat.

Roughly following Frege (1948), thoughts and other representations are sometimes taken to have two kinds of semantic features: sense and reference. On one intuitive way of characterizing this distinction, a representation's referent is what it picks out, singles out, or refers to, while its sense is the way in which this (putative) referent is conceived. While Frege argued that senses are publicly available abstract entities that determine reference, on my use of the term "sense," I will not assume that senses have any of these features. A representation's sense is merely how its subject conceives of its (putative) referent.

One gloss on Frege's arguments for the existence of senses is that we need them in order to account for semantic differences that are not differences in reference. For example, the thought that Hesperus is bright and the thought that Phosphorus is bright involve all the same referents but differ in meaning or "cognitive significance." We can account for this difference by saying that the two thoughts contain two distinct concepts, Hesperus and Phosphorus, with different senses. The sense of Hesperus is < the first star visible in the evening sky >, while the sense of Phosphorus is < the last star visible in the morning sky $>$. The two concepts pick out the same thing but involve two different ways of conceiving of it.

My contention is that, while this is more or less the right picture, we need to make a further distinction between two different kinds of sense corresponding to two different ways of understanding what it is to conceive of a (putative) referent in a certain way. One way of understanding the notion of conceiving of

\footnotetext{
${ }^{2}$ This is to assume something like a language of thought (see Fodor 1975).
} 
a (putative) referent is as capturing what is in some sense "before one's mind" when we use a concept or have a thought. This is what is running through our minds, what is immediately available to us, or what we are aware of in using a representation. Call this a representation's immediate sense. To say that $<$ the first star visible in the evening sky $>$ is the immediate sense of HesPerus is to say that when we use the concept Hesperus, the content $<$ the first star visible in the evening sky $>$ is running through our minds.

Another way of understanding the notion of conceiving of a referent is as capturing our reflective intuitive understanding of a referent, an understanding we might retrieve upon brief or prolonged reflection. Call this a representation's reflective sense. To say that $<$ the first star visible in the evening sky $>$ is the reflective sense of HESPERUS is to say that when we use the concept HESPERUs, the content $<$ the first star visible in the evening sky $>$ is available upon sufficient reflection of the right sort. For instance, if we were to think $<$ Hesperus is bright $>$, upon sufficient reflection we should be able to further elucidate our thought as $<$ the first star visible in the evening sky is bright $>$, accepting this as what we meant, intended, or targeted by the first thought.

\section{A Distinction with a Difference}

So far I have merely introduced the notions of immediate and reflective senses. In this section, I argue that there are immediate and reflective senses and that they are distinct. I do so by considering a variety of examples, focusing mainly on concepts, and arguing that they involve two distinct things respectively answering to the notions of immediate and reflective senses. ${ }^{3}$

\footnotetext{
${ }^{3}$ We might also argue for the distinctness of immediate and reflective senses in a way that parallels our gloss on Frege's argument for the existence of senses: We need immediate senses that are distinct from reflective senses in order to account for differences that are not differences in either reflective senses or referents. For example, suppose that we reflectively understand a bachelor as an unmarried man. The thought that John is a bachelor and the
} 
Number concepts. My first example is adapted from David Bourget's (2017) discussion of number concepts. When we think about numbers, especially large numbers, we are not immediately aware of the numbers themselves but rather of the numerals that stand for them, perhaps in addition to a rough ballpark sense of their magnitudes. Bourget offers a couple of reasons to think this: First, as far as what is in our immediate awareness is concerned, numerals like " $8,346,182$ " could stand for entirely different numbers than they in fact stand for. Second, the same arithmetical equation can seem more or less obvious depending on the notation used to symbolize it. For example, $70 \times 100=7000$ is obvious when presented in decimal notation but less obvious when presented in binary notion $(1000110 \times 1100100=1101101011000)$. All this suggests that the immediate senses of most of our number concepts are not numbers but something more like numerals.

However, our reflective understanding of numbers goes beyond what's in our immediate awareness. There are different possible views of exactly what this understanding consists in. Perhaps we understand numbers as multiplicities, abstract entities with various features, whatever entities satisfy certains axioms, something to do with counting or the succession relation, or even sui generis entities.

If all this is right, then our number concepts have distinct immediate and reflective senses. Their immediate senses are something like numerals, while their reflective senses encompass a richer understanding, such as that of a multiplicity

thought that John is an unmarried man involve the same reflective senses and referents but are different thoughts. We can account for this difference by saying that the two thoughts involve two distinct concepts, BACHELOR and UNMARRIED MAN, with distinct immediate senses. The difference between the two thoughts lies in what we are immediately aware of in having them.

One might object that the difference between the two thoughts can be accounted for by the different vehicles they involve. While the two thoughts do involve different vehicles, this does not fully account for the difference between them because the difference is a semantic difference, a difference in what we are thinking. In order to account for this semantic difference, we need to posit a difference in the semantic features involved in these cases. (See also Mendelovici 2010: \$13.4, for related discussion of how distinguishing between immediate and reflective senses best resolves the paradox of analysis.) 
or an abstract object.

Stipulated concepts. Suppose that, while developing a philosophical argument, you stipulate $<$ let Ent $=$ physicalism is committed to the a priori entailment of the phenomenal facts by the physical facts $>$. You thereby acquire a new concept, ENT, which you can use in your further deliberations.

When you have a thought involving ENT, <physicalism is committed to the a priori entailment of the phenomenal facts by the physical facts $>$ is not running through your head in its entirety. Instead, what is running through your head - call it $\langle E n t\rangle$ - might consist in purely verbal or perceptual imagery of the word "Ent," a schematic, gist-like, or partial understanding of $<$ physicalism is committed to the a priori entailment of the phenomenal facts by the physical facts $>$, or perhaps a new simple or sui generis content. Different people or the same people on different occasions might enjoy different immediate senses associated with the concept ENT.

$<$ Ent $>$ 's lack of detail and complexity is what makes your stipulation useful to you, lessening your cognitive load by allowing you to use a simpler content to stand for one that is more complex. In the extreme case, these kinds of stipulations allow you to engage in purely formal reasoning about complex, substantive issues, just as we can reason about large numbers by manipulating numerals that stand for them.

At the same time, your reflective understanding of the target of ENT is the more complex $<$ physicalism is committed to the a priori entailment of the phenomenal facts by the physical facts $>$. This is what you stipulated $<$ Ent $>$ is to stand for, and it can be easily retrieved by you at any point in your deliberations.

If all this is right, then ENT's immediate sense is $<$ Ent $>$, whatever that ends up being, while its reflective sense is $<$ physicalism is committed to the a priori 
entailment of the phenomenal facts by the physical facts $>$. The same holds in other cases of stipulated concepts.

Concepts with definitions. Similar points hold for non-stipulated concepts that have definitions, such as the concepts GRANDMOTHER, ODD NUMBER, and SUPERVENIENCE. These concepts' definitions arguably capture our reflective understanding of their targets, but they do not run through our heads every time we use the concepts. For example, when you think $<$ three is an odd number $>$, you are not immediately aware of any definition of an odd number-for instance, you are not immediate aware of the property of being divisible or the number two. Likewise, when you think < the mental supervenes on the physical $>$, you are not immediately aware of possible worlds or other elements in SUPERVENIENCE's definition.

Although a defined concept's definition is not usually running through your mind when you use it, there is something running through your mind, so defined concepts also have immediate senses. In the case of SUPERVENIENCE, for example, this immediate sense might be or involve some verbal or perceptual imagery (e.g., the word "supervenience" or mental imagery of one item above another), a schematic, gist-like, or partial grasp of the definition of supervenience (e.g., an abstract idea of some kind of logical dependence), or simple or sui generis contents, not understandable in terms of other contents (e.g., as far as our immediate understanding of supervenience is concerned, supervenience might be a simple or sui generis relation, its own kind of thing). As in the case of concepts with stipulated definitions, different people or the same people on different occasions might enjoy different immediate senses associated with the concept SUPERVENIENCE.

If all this is right, then concepts with definitions have immediate and reflective 
senses, and they are usually distinct.

Prototype, exemplar, and theory concepts. Many everyday concepts like TABLE and CHAIR arguably do not have definitions. One reason to think this is that it is notoriously difficult to produce satisfactory definitions for such concepts. Another reason is that there is a host of empirical findings suggesting that most concepts do not have a definitional structure. ${ }^{4}$

Alternative views of such concepts take them to represent or involve the representation of prototypes, which are (perhaps weighted) lists of features that members of a category tend to have or that are predictive of belonging to a category (Rosch 1975, Rosch and Mervis 1975) sets of exemplars, which are individual items or subcategories that fall under a category (Medin and Schaffer 1978, Brooks 1978) or theories about a category (Murphy and Medin 1985, Carey 1985, Gopnik and Wellman 1994).

If the prototype, exemplar, or theory theories are right about certain concepts, then our reflective understanding of the categories they pick out likely consists in the information stored in our prototypes, exemplars, or theories of the category, respectively. For example, how we conceive of the target of our concept BIRD upon reflection might be a matter of our bird prototype, our stored exemplars of birds, or our theoretical information about birds, depending on the theory. But when we use the concept BIRD, we are not immediately aware of a bird prototype, multiple exemplars of birds, or theories of birds. Still, there is something running through our minds when we think about birds. This might be a matter of verbal imagery corresponding to the word "bird"; mental imagery of a bird; a schematic, gist-like, or partial understanding of our prototypes, exemplars, or the information in our theories; or a simple or sui generis content. ${ }^{5}$

\footnotetext{
${ }^{4}$ For an overview, see Murphy 2004

${ }^{5}$ There is an important caveat: Some aspects or parts of the prototypes, sets of exemplars,
} 
If all this is right, then concepts with an exemplar, prototype, or theory structure have distinct immediate and reflective senses. What we are immediately aware of in using such concepts differs from our reflective understanding of their targets.

Perceptual experiences. In many perceptual experiences, immediate and reflective senses do not come apart. Many of the targets of perceptual experience are presented to us just as we reflectively understand them. Suppose you visually experience something as having a specific shape for which you have no corresponding concept. Your entire grasp of the nature of the shape is in some sense immediately before your mind's eye. What you immediately understand of the shape is the same as what you reflectively understand of it. So, the experience's immediate sense is the same as its reflective sense. ${ }^{6}$

But there are two kinds of cases in which the immediate and reflective senses of a perceptual experience can come apart. The first involves the representation of high-level properties, like the properties of being a cat or a computer (see Siegel 2005). Suppose you see a computer as a computer. And suppose further that your reflective understanding of computers includes a definition, prototype, set of exemplars, or theory of computers. When you see the computer as a computer, you are not immediately aware of such definitions, prototypes, exemplars, or theories. But, at the same time, you are immediately aware of more than just the low-level features that your experience represents. In seeing the computer as

or theories that are associated with a given concept might not be available upon reflection but might nonetheless do other work that would justify their inclusion in a concept's prototype, set of exemplars, or theory. For instance, they might only be involved in categorization-for example, we might categorize objects as dogs based partly on their having a certain dog smell, but it might not be part of our reflective understanding of dogs that they have such a smell. Indeed, it is even possible for no parts of a concept's prototype, set of exemplars, or theory to constitute our reflective understanding of its target. This might be the case with concepts with definitions that nonetheless have associated prototypes, exemplars, or theories, such as the concept GRANDMOTHER.

${ }^{6}$ See also Bourget's (2017) example of perfectly grasping the shape of a line drawing. 
a computer, you might be aware of verbal imagery corresponding to the word "computer," a generic or schematic image of a computer, a gist-like or schematic understanding of your reflective conception of computers, or a simple or sui generis content. Something similar holds in other cases of high-level property representation in perception. If this is right, then the immediate and reflective senses of perceptual representations of high-level properties differ.

Immediate and reflective senses also come apart when we have a conceptual understanding of low-level features represented in perception that goes beyond our perceptual grasp of those features. For example, suppose you perceptually experience a square. Your reflective conceptual grasp of squareness might involve a definition of a square as a closed plane figure with four sides of equal length that meet at right angles. Your experience, however, does not involve an immediate awareness of this definition. What you are immediately aware of is a particular experienced shape, perhaps together with verbal or perceptual imagery, or some additional gist-like appreciation of squareness.

In some cases, an experience's immediate sense can be in tension with its reflective sense. Suppose that your color experiences represent primitive colors, while your color concepts represent dispositions to cause color experiences. Suppose now that you experience an apple as red. You are immediately perceptually aware of primitive redness. However, what you understand upon reflection is a disposition to cause experiences of redness. Your experience's immediate sense is $<$ primitive redness $>$, but its reflective sense is $<$ disposition to cause experiences of primitive redness $>.^{7}$

In summary, the immediate senses of many perceptual experiences are the same as their reflective senses. In such cases, we are immediately aware of exactly

\footnotetext{
${ }^{7}$ Suppose that objects have dispositions to cause color experiences but do not have primitive colors. Then your experience is both accurate with respect to its reflective sense and inaccurate with respect to its immediate sense. For further discussion, see also Mendelovici 2018 Appendix D.
} 
what constitutes our reflective understanding of a representation's referent. In other cases, however, immediate senses and reflective senses come apart.

I've considered various concepts and other representations and argued that they have immediate and reflective senses. We've seen that in the case of concepts and perceptual representations that involve something like a "conceptual" element, the two kinds of sense come apart. Since thoughts are composed of concepts, and assuming that the senses of thoughts involve or are a function of the senses of their constituent concepts, it is reasonable to conclude that thoughts also have immediate and reflective senses and that these senses often come apart. ${ }^{8}$

\section{Against Tracking and Functional Role Theo- ries of Immediate and Reflective Senses}

Immediate and reflective senses are semantic features of mental states, so we might turn to contemporary theories of intentionality for an account of them. In this section, I will very briefly consider two prominent contemporary theories of intentionality - tracking and functional role theories - and suggest that their main ingredients cannot account for either kind of sense. In the next section, I will consider an alternative theory - the phenomenal intentionality theory - and argue that its ingredients can.

According to tracking theories, what a representation represents is or is determined by what it tracks, where tracking is detecting, carrying information about, or otherwise appropriately corresponding to states of affairs or other items

\footnotetext{
${ }^{8}$ It is also possible to argue for the claim in the case of thoughts in much the same way as I've argued for the claim in the case of concepts: through the consideration of various cases. For example, we might directly argue that the reflective sense of the thought that the mental supervenes on the physical differs from its immediate sense.
} 
in the environment. On many tracking theories, the relevant tracking relation is a causal relation (e.g., Stampe 1977, Dretske 1995, Fodor 1987, Neander 2017), though on others it is not (Millikan 1984).

One might suggest that we can account for immediate and reflective senses in terms of tracking relations. The problem with such an account is that, in many cases, what we track comes apart from how we understand something both immediately and reflectively. For example, a child's color concepts might track various surface reflectance properties or dispositions to affect us in certain ways, but when she experiences colors, she is only immediately aware of a primitive, sui generis property of objects. So what her perceptual color representations track doesn't match their immediate senses. Her reflective understanding of colors might also be as of primitive, sui generis properties, so what her color concepts track doesn't match her reflective understanding of colors either. If this is right, the tracking theory cannot account for either kind of sense. ${ }^{9}$

Let us now consider functional role theories, which state that a mental state's content is or is determined by its inferential or other kind of functional role (see Harman 1987, Block 1986). For example, the representation BACHELOR might represent < unmarried man > in virtue of being involved in the following inferences:

(B1) From judging O IS A BACHELOR, one is likely to judge O IS A MAN.

(B2) From judging O IS A BACHELOR, one is likely to judge O IS UNMARRIED.

(B3) From judging O IS A MAN and o IS UNMARRIED, one is likely to judge o IS A BACHELOR.

Unfortunately, functional roles are ill-suited to accounting for immediate

\footnotetext{
${ }^{9}$ For objections to tracking theories along these lines, see Mendelovici 2013, 2016, 2018 ch. 3 and Mendelovici and Bourget forthccming
} 
senses. For example, the concept ENT might be taken to be involved in the following key inferences:

(E1) From judging Ent, one is likely to judge PHYSICALISM IS COMMITTED TO THE A PRIORI ENTAILMENT OF THE PHENOMENAL FACTS BY THE PHYSICAL FACTS.

(E2) From judging PHYSICALISM Is COMMitTed to the A PRIORI ENTAILMENT OF THE PHENOMENAL FACTS BY THE PHYSICAL FACTS, one is likely to judge EnT.

But this pattern of inferences most closely captures ENT's reflective sense, not its immediate sense. The problem is that ENT behaves as if it stands for its stipulated definition - indeed, that is why it can be so useful ${ }^{10}$

A functional role approach is more promising as an account of reflective senses, as illustrated by the case of ENT. However, such an account faces a challenge, which is a special case of what is sometimes called the "problem of collateral information" (see Block 1986): Not all of a representation's inferential or other functional roles determine its reflective sense. For example, in addition to (B1)-(B3), BACHELOR might play the following role:

(B4) From judging o is a BACHELOR, one is likely to judge O LIVES ALONE.

But (B4) does not play a role in determining BACHELOR's reflective sense, which, presumably, is something like $<$ unmarried man $>$, not $<$ unmarried man who lives alone $>$. The functional role approach needs a way of distinguishing the functional roles that play a role in determining reflective senses from those that merely capture collateral information we have about a representation's target.

\footnotetext{
${ }^{10}$ I have only considered "short-arm" (Harman 1987) functional role theories, which take functional roles to be internal roles. "Long-arm" (Harman 1987) functional role theories appeal to causal or other relations to the environment in addition to internal roles. Including such relations does not help us accommodate immediate senses, since there are many cases in which immediate senses do not match anything we are interestingly related to in the environment (e.g., the case of color representations mentioned earlier). See also Mendelovici $2018 \S 4.3$.
} 
I will later suggest that an account of reflective senses that invokes both functional roles and phenomenal consciousness can meet this challenge. For now, however, I want to suggest that an account of reflective senses in terms of functional roles alone is incorrect because it neglects the relationship between immediate and reflective senses.

Reflective senses are available upon reflection. If we were to reflect sufficiently, they would be immediately available to us, just like immediate senses. This suggests that a representation's having a reflective sense is a matter of our being disposed to bring to mind a particular immediate sense. The immediate sense need not be the immediate sense of the representation in question but might instead be the immediate sense of another representation. For example, ENT's having the reflective sense $<$ physicalism is committed to the a priori entailment of the phenomenal facts by the physical facts $>$ is a matter of our being disposed to retrieve a distinct complex representation with that content as its immediate sense. All this accords with the phenomenology of retrieval of reflective senses. Reflective senses, when they are retrieved, seem like the same kind of thing as immediate senses. Like immediate senses, retrieved reflective senses are immediately available to us. On this picture, one representation's reflective sense is another representation's immediate sense. ${ }^{11}$

If this picture of reflective senses is correct, then an account of reflective senses in terms of functional roles alone is incorrect because it does not make

\footnotetext{
${ }^{11} \mathrm{I}$ have suggested a picture on which reflective senses are a matter of dispositions to entertain immediate senses. An alternative picture would take reflective senses to be somehow inherent in representations themselves. One reason to prefer the dispositional picture is that it makes better sense of why we need to retrieve our representations' reflective senses in order to complete certain tasks. For example, in order to judge whether a necessary God supervenes on everything, we might need to retrieve the reflective sense of SUPERVENIENCE. Another reason to prefer the dispositional picture is that it makes better sense of how we can sometimes fail to retrieve our reflective senses. For example, Gabriel might suddenly find that while he can entertain the immediate sense of SUPERVENIENCE just as he could before, and, e.g., think thoughts like < the mental supervenes on the physical $>$, he is no longer able to unpack the concept. This would be odd if the reflective sense of SUPERVENIENCE were somehow inherent in the concept itself. (See also Mendelovici 2010 ch. 10, especially n. 23.)
} 
reference to immediate senses, aiming instead to account for reflective senses directly.

\section{Accounting for Immediate and Reflective Senses: The Phenomenal Intentionality Theory}

This section outlines an alternative approach to intentionality, the phenomenal intentionality theory: ${ }^{12}$ and argues that it has the resources needed to neatly account for both immediate and reflective senses.

According to the phenomenal intentionality theory (PIT), there is a kind of intentionality, phenomenal intentionality, that is nothing over and above phenomenal consciousness, the "what it's like" (Nagel 1974) aspect of mental life, and all other kinds of intentionality are derived from it. Phenomenal intentionality might be identical to, constituted by, grounded in, or in some other way nothing over and above phenomenal consciousness, and derived intentionality might derive from it in various ways. ${ }^{13}$ For example, a perceptual intentional state with the content $<$ red square $>$ might be identical to a reddish squarish phenomenal state, and a concept of redness might derive its content from its relation to such possible or actual phenomenal intentional states. We can call contents that are phenomenally represented phenomenal contents and contents that are derivatively represented derived contents. In the previous example, the perceptual state has a phenomenal content and the concept has a

\footnotetext{
${ }^{12}$ See Loar 2003, Strawson 1994, Siewert 1998, Horgan and Tienson 2002, Horgan and Graham 2009 Pitt 2004 Farkas 2008, Kriegel 2011, Bourget 2010a 2010b, Mendelovici 2010. 2018. Bourget and Mendelovici 2016 and Mendelovici and Bourget 2014, forthccming

i3 Phenomenal intentionalists have proposed various derivation mechanisms. For example, Horgan and Tienson (2002) suggest that wide intentional states are derived from phenomenal intentional states together with "grounding presuppositions" and facts about the world, Bourget (2010a) takes non-phenomenal intentional states to derive from phenomenal intentional states via descriptive reference and other derivation mechanisms, and Kriegel (2011) maintains that non-conscious intentional states are derived from the phenomenal intentional states of an ideal rational agent.
} 
derived content.

On the face of it, PIT appears to have the right structure to accommodate both kinds of senses. Let us say that the PIT approach to immediate and reflective senses is the claim that immediate senses are phenomenal contents and reflective senses are derived contents.

It is plausible that immediate senses are phenomenally represented. Immediate senses are immediately available to us upon having a thought or other representational state in the same way that phenomenal characters are typically available to us upon having a phenomenal experience. This accords with the view that immediate senses are phenomenal contents. Relatedly, taking immediate senses to be phenomenal contents goes some way towards explaining why they are immediately available to us: They are phenomenally conscious.

It is also plausible that reflective senses are derived from phenomenal contents. In the previous section, I argued that having a reflective sense is a matter of being disposed to entertain an immediate sense upon reflection. On this picture, immediate senses are more basic than reflective senses, and reflective senses are derived from them. If this is right, and if immediate senses are phenomenal contents, then reflective senses are derived from phenomenal contents, as the PIT approach claims.

Many details of the PIT approach remain to be worked out. First, since thoughts have immediate senses, the PIT approach requires that they also have phenomenal characters and that these phenomenal characters match their immediate senses. Second, the PIT approach must offer an account of precisely how reflective senses derive from immediate senses. Third, something must be said about nonconscious occurrent states, which might be taken to have immediate senses but no phenomenal characters. In the next three subsections, I will briefly consider these issues in turn. 


\subsection{The Phenomenology of Thought}

Since thoughts have immediate senses, the PIT approach requires them to have phenomenal characters that match their immediate senses. Whether thoughts have phenomenal characters and of what sort is a hotly debated issue ${ }^{14}$ The debate usually focuses on what is sometimes called the cognitive phenomenology thesis, the thesis that thought has a proprietary and individuative phenomenology. Thought has a proprietary phenomenology just in case the phenomenology of thought is "cognitive," or non-sensory, i.e., different in kind from the phenomenology of sensory mental states like perceptual experiences and emotions. Thought has an individuative phenomenology just in case thoughts with different contents have different phenomenal characters and thoughts with different phenomenal characters have different contents.

For present purposes, we can largely avoid the debate over the cognitive phenomenology thesis. This is because the kind of phenomenology of thought required for PIT to account for immediate senses needn't be proprietary and it needn't be individuative in the sense that is least plausible. It need not be proprietary because as far as what we've said about immediate senses is concerned, immediate senses could be sensory in character. For example, they might consist in verbal or perceptual imagery, which, quite plausibly, would only require verbal or perceptual phenomenology. Whether this view is viable depends on whether verbal and perceptual contents can plausibly capture both the immediate senses of thoughts and the reflective senses that derive from them. In other words, it depends on whether we think a kind of empiricism is true of immediate and reflective senses. ${ }^{15}$

\footnotetext{
${ }^{14}$ Bayne and Montague 2011 for a representative collection of essays.

${ }^{15}$ See Prinz 2002 for a recent defense of empiricism. Although Prinz combines his empiricism with a tracking view of intentionality, it can also be quite plausibly combined with the PIT approach.
} 
Whether the PIT approach requires the phenomenology of thought to be individuative depends on how we understand what it is for thought's phenomenology to be individuative. We said that thought has an individuative phenomenology just in case thoughts with different contents have different phenomenal characters and thoughts with different phenomenal characters have different contents, but we didn't specify what are the relevant thought contents. Two different understandings of being individuative are relevant to our purposes, one on which we understand the relevant kind of contents to be reflective senses and one on which we understand them to be immediate senses. The phenomenology of thought is individuative-with-respect-to-reflective-senses just in case thoughts with the same reflective senses have the same phenomenal characters and thoughts with the same phenomenal characters have the same reflective senses. The phenomenology of thought is individuative-with-respect-to-immediate-senses just in case thoughts with the same immediate senses have the same phenomenal characters and thoughts with the same phenomenal characters have the same immediate senses.

Since the PIT approach takes immediate senses, but not reflective senses, to arise from phenomenal character alone, it requires the phenomenology of thought to be individuative-with-respect-to-immediate-senses but does not require it to be individuative-with-respect-to-reflective-senses. This is arguably a quite plausible view of the phenomenology of thought. To see this, consider a case that challenges the view that thought has an individuative phenomenology:

Dimitri and Dimitra have different reflective understandings of what it is to be a father. For Dimitri, a father is a biological father, whereas for Dimitra, a father is a person with a male gender identity and a parental role. This difference in Dimitri and Dimitra's concepts of a father is not always reflected in the phenomenal characters of their thoughts about fathers, especially when 
questions of biological fatherhood or parental roles are not particularly salient. When Dimitri and Dimitra think the thoughts they would express with "Marius is a father," their thoughts sometimes have the same phenomenal characters. This is a counterexample to the phenomenology of thought being individuativewith-respect-to-reflective-senses, since Dimitri and Dimitra's thoughts have the same phenomenal characters but different reflective senses. But it need not be a counterexample to the phenomenology of thought being individuative-withrespect-to-immediate-senses. If Dimitri and Dimitra's thoughts have the same phenomenal characters, then it is quite plausible that Dimitri and Dimitra are immediately aware of the same thing and so that their thoughts have the same immediate senses. This example shows that relatively deep theoretical differences of the sort exemplified by Dimitri and Dimitra make a difference for reflective senses but they need not make a difference for phenomenal characters or immediate senses. This suggests that the phenomenology of thought is individuative-with-respect-to-immediate-senses, as required by the PIT approach, but not individuative-with-respect-to-reflective-senses.

In summary, although the PIT approach to immediate and reflective senses requires there to be a phenomenology of thought, this requirement is not as controversial as it might seem, since the phenomenology of thought need not be proprietary or individuative-with-respect-to-reflective-senses. Even opponents of the cognitive phenomenology thesis might agree that thoughts have the kind of phenomenology required.

The PIT approach requires not just that thoughts have phenomenal characters but also that their phenomenal characters can plausibly be identified with their immediate senses. In many cases, such an identification is not implausible. For example, ENT's immediate sense might simply be a verbal representation of the word "Ent" together with a gist-like awareness of physicalism's commitment to 
a priori entailment, and its phenomenal character might involve some verbal phenomenology of the word "Ent" and a gist-like cognitive phenomenal character. Similarly, a concept of a large number might have an immediate sense consisting of an auditory or visual depiction of the numeral that stands for it and a matching auditory or visual phenomenal character.

Something similar holds in other cases. While it might be unclear what exactly are the immediate senses of representations like BIRD and SUPERVENIENCE, it is not implausible that they match their phenomenal characters in the way required. Immediate senses might consist in verbal or perceptual imagery, gists or aspects of reflective senses, or primitive or sui generis contents. This allows for a variety of views of the phenomenal character of any given representation on which it matches its immediate sense: First, the representation might have a verbal immediate sense and a matching verbal phenomenology (e.g., SUPERVENIENCE might have the word "supervenience" as its immediate sense and a matching quasi-auditory verbal phenomenal character). Second, the representation might have a perceptual immediate sense and a matching perceptual phenomenology (e.g., SUPERVENIENCE might have an immediate sense consisting in mental imagery of one item above another and a matching visual phenomenal character). Third, the representation might have a simple or sui generis immediate sense and a matching simple or sui generis phenomenal character (e.g., SUPERVENIENCE might have a simple or sui generis immediate sense, not understandable in terms of any other contents, and a matching simple or sui generis supervenience-ish phenomenal character). Fourth, the representation might have an immediate sense that is a component or aspect of its reflective sense (which might be a matter of perceptual and verbal imagery, simple or sui generis components, or something else) and a matching phenomenal character that is a component of the phenomenal character corresponding to its reflective sense (e.g., SUPERVENIENCE 
might have the immediate sense $<$ no difference without a difference $>$, where this is a matter of verbal, or simple or sui generis contents, and a phenomenal character consisting in matching perceptual, verbal, or simple or sui generis phenomenal characters). Finally, the representation might have an immediate sense consisting of a schematic or gist-like understanding of at least some aspects of its reflective sense and a similarly schematic or gist-like phenomenal character (e.g., SUPERVENIENCE might have an unarticulated or gist-like grasp of its definition as its immediate sense and a similarly gist-like phenomenal character).

These options can be combined in various ways. First, a single representation might have an immediate sense that is a combination of the above options and a similarly combined phenomenal character. For example, SUPERVENIENCE's immediate sense and phenomenal character might contain both verbal and sui generis components. Second, different representations might have different kinds of immediate senses and phenomenal characters. Perhaps BIRD's immediate sense and phenomenal character consist in perceptual imagery and perceptual phenomenal character, respectively, but KNOWLEDGE's immediate sense and phenomenal character are sui generis. Third, different subjects or the same subject on different occasions might have representations with different immediate senses and phenomenal characters, even if they have the same reflective senses- just like Dimitri and Dimitra. ${ }^{16}$

One potentially attractive view is that the immediate senses and phenomenal characters of many representations are both simple, in that they do not involve component parts, and gist-like, in that they involve hints of at least some aspects of their reflective senses. This might be possible if immediate senses (phenomenal characters) are internally unstructured, in that they do not involve proper parts that are also immediate senses (phenomenal characters), and at the same

\footnotetext{
${ }^{16}$ For further discussion, see Mendelovici 2018 \$7.2.4.
} 
time externally structured, in that they differ from various other actual or possible immediate senses (phenomenal characters) along various dimensions. ${ }^{17}$ We can think of such externally structured immediate senses (phenomenal characters) as being located in multidimensional spaces of immediate senses (phenomenal characters) organized by similarity.

For example, the immediate senses (phenomenal characters) of perceptual color representations are arguably internally unstructured: they do not have or decompose into proper parts that are also immediate senses (phenomenal characters). For example, the phenomenal character of an experience of green arguably isn't composed of phenomenal characters corresponding to particular hues, saturations, brightnesses, or distinct full-fledged colors. ${ }^{18}$ But it is externally structured: It differs from the phenomenal characters of other color experiences with respect to hue, saturation, and brightness. The same arguably holds for the experience's immediate sense.

More speculatively, perhaps the immediate senses (phenomenal characters) of some concepts can be located in the same multidimensional spaces as their reflective senses (their reflective sense's phenomenal characters). For instance, perhaps the immediate sense of KNOWLEDGE has some features in common with those of JUSTIFICATION and BELIEF, and its similarity to those immediate senses accounts for the sense we have that the immediate sense of KNOWLEDGE is a gist-like grasp of at least some components of its reflective sense. All this is compatible with the immediate sense of KNOWLEDGE being internally simple - it might not have immediate senses such as $<$ belief $>$ and $<$ justification $>$ as parts, in the same way that the immediate senses of perceptual color representations do not have immediate senses corresponding to hues, saturations, and brightnesses as parts. The same arguably holds for the concept's phenomenal character.

\footnotetext{
${ }^{17}$ This terminology comes from Chalmers 2016

${ }^{18}$ See Roelofs 2014 for arguments to the contrary and Mendelovici 2019 for discussion.
} 
My preferred view of the immediate senses and phenomenal characters of most concepts is that they are simple and gist-like in this way, perhaps also in some cases involving a verbal component and some mental imagery. This accords with the phenomenology of consciously entertaining immediate senses. When we think <the mental supervenes on the physical>, we seem to have both a grasp of supervenience as its own unique thing as well an inarticulate glimpse of its reflective sense. In any case, my main claims are compatible with other views of the immediate senses and phenomenal characters of concepts and other representations.

\subsection{How reflective senses derive from phenomenal con- tents}

The PIT approach takes reflective senses to derive from phenomenal contents. But how exactly does this derivation work?

In Section 4, I suggested that a representation's reflective sense is a matter of the immediate senses we are disposed to retrieve upon reflection. For example, upon reflection of $<$ Ent $>$, we are disposed to retrieve the immediate sense $<$ physicalism is committed to the a priori entailment of the phenomenal facts by the physical facts $>$, which is ENT's reflective sense. This suggests a way in which reflective senses derive from phenomenal contents: A representation's reflective sense derives from the phenomenally represented immediate senses we are disposed to retrieve upon reflection of its immediate sense.

The central challenge for such an account of reflective senses is to make sense of what it is for an immediate sense to be retrieved upon reflection. This cannot just be a matter of being disposed to entertain it after entertaining the representation in question's immediate sense, since we might be similarly disposed to entertain immediate senses that are not relevant to determining reflective 
senses. For example, upon entertaining the immediate sense $<$ bachelor $>$, we might be disposed to entertain immediate senses such as <unmarried man>, $<$ lives alone $>$, and < bachelorette $>$, but only the first of these is BACHELOR's reflective sense.

The challenge is analogous to the functional role theory's problem of collateral information discussed in $\S 4$. The situation, however, is importantly different for the PIT approach than for a functional role approach, since the PIT approach does not aim to understand reflective senses in entirely non-semantic terms but instead accepts phenomenal intentional states as part of its explanatory base.

My proposal takes its cue from non-mental cases of derived representation. Words, signs, and other non-mental items can come to have contents thanks to antecedently contentful mental states. For example, the word "dog" might mean $<\operatorname{dog}>$ and stop signs might mean $<$ stop $>$ because we take "dog" to mean $<\operatorname{dog}>$ and stop signs to mean $<$ stop $>$. This taking is at least partly a matter of our representational states, such as our beliefs, intentions, and stipulations.

I want to suggest that the relation between mental representations and their reflective senses is similar to the relation between non-mental derived representations and their contents. Just as we take words and signs to have certain contents, so too do we take mental representations to have certain contents beyond their immediate senses. On this proposal, BACHELOR has the reflective sense $<$ unmarried man $>$ because we take it to represent $<$ unmarried man $>$. This taking is a matter of being disposed to accept <unmarried man> as equivalent to, what is meant by, or a further elucidation of the immediate sense of BACHELOR, < bachelor $>$. This might involve being disposed to entertain the immediate sense < unmarried man, that's the same as a bachelor $>$, or $<$ bachelors are just unmarried men $>$. Such thoughts - call them cashing out thoughts - say that one content is an elucidation, unpacking, precisification, 
expansion, or more generally a cashing out of another.

In many cases, it takes multiple cashing out thoughts to retrieve a full elucidation of a representation's immediate sense. For example, we might be disposed to have cashing out thoughts relating $<$ bachelor $>$ to $<$ unmarried man $>$, $<$ unmarried $>$ to $<$ not married $>$ and $<$ man $>$ to $<$ human male $>$. Assuming (probably falsely) that we are not disposed to have cashing out thoughts relating $<$ not married $>$ and $<$ human male $>$ to further contents, $<$ not married human male $>$ is what we might call BACHELOR's full cashing out. This content reflects our best understanding of BACHELOR's target - it is BACHELOR's reflective sense. My suggestion, then, is that a concept's reflective sense is its full cashing out. ${ }^{19}$

This provides a way of solving our analogue of the problem of collateral information: What singles out $<$ not married human male $>$ and not $<$ unmarried man who lives alone $>$ as the reflective sense of BACHELOR is that we are disposed to have cashing out thoughts specifying that $<$ bachelor $>$ cashes out into $<$ not married human male $>$ but we are not disposed to have cashing out thoughts specifying that $<$ bachelor $>$ cashes out into $<$ unmarried man who lives alone $>$.

This picture of reflective senses is cursory and much more needs to be said before its viability can be assessed. However, I hope this section has at least shown in outline how reflective senses might be derived from phenomenal contents. ${ }^{20}$

\footnotetext{
${ }^{19}$ A representation's full cashing out is an immediate sense or at least a content specified by an immediate sense (see Mendelovici 2018 §7.3.1, p. 142). There is good reason to think that, at least for concepts whose target we claim to somewhat understand, we can reach such an understanding in terms of immediate senses. If we couldn't, then we would have no claim to understanding them. It is an open question, however, what kinds of immediate senses we will find in a representation's full cashing out. For instance, we might find perceptual contents, but we might also find unanalysable non-perceptual contents, perhaps like $<$ good $>$ or $<$ knowledge $>$.

${ }^{20}$ This kind of view is developed in more detail in Mendelovici $2018 \mathrm{ch}$. 7 . Note that there I employ a definition of "intentionality" on which derived contents, and hence reflective senses, do not qualify as genuinely intentional contents, though they qualify as representational in a looser, everyday sense.
} 


\subsection{Nonconscious occurrent states}

The third issue for the PIT approach concerns nonconscious occurrent states that are arguably representational in some sense. Occurrent states are states that are active, used, or undergone, such as perceptual states or thoughts. Nonconscious states are mental states that lack phenomenal character. Some nonconscious occurrent states are arguably representational in some sense, e.g., some states involved in language processing or early perceptual processing. Since nonconscious occurrent representational states are nonconscious, they presumably lack phenomenal characters, which commits the PIT approach to saying that they also lack immediate senses. But, since nonconscious occurrent representational states are occurrent and representational, it seems they should have immediate senses - when we have such states, their contents should be immediately available to us or "running through our minds," even if we are not consciously aware of them.

Nonconscious occurrent states pose a challenge for PIT in general, not just for the PIT approach to immediate and reflective senses. Accordingly, the positions the PIT approach might take towards them correspond to the positions available to PIT, which are the following: (1) They phenomenally represent their contents (e.g., Pitt MS , Bourget 2010a, Mendelovici 2018: ch. 8); (2) they derivatively but not phenomenally represent their contents (e.g., Bourget 2010a, Kriegel 2011); and (3) they do not phenomenally or derivatively represent their contents, though they might "represent" them in some other sense (e.g., Searle 1990, Mendelovici 2018: ch. 8).

For the PIT approach, option (1) allows that nonconscious occurrent states have immediate senses and, if the right dispositions are in place, reflective senses. One might worry that this option requires that we can have phenomenal states that we are not introspectively aware of, but, given that there exist many 
phenomenal states that any given individual is not consciously aware of (e.g., the phenomenal states of other subjects), it is not wholly implausible that our own heads harbor phenomenal states that are likewise isolated from our introspective abilities.

Option (2), on which nonconscious occurrent states derivatively represent their contents, results in the view that nonconscious occurrent states lack immediate senses but nonetheless have reflective senses. On this view, when a representation gets used nonconsciously, we are not immediately aware of anything. However, despite lacking immediate senses, nonconscious occurrent states have reflective senses, which derive from immediate senses. Since nonconscious occurrent states lack immediate senses, their reflective senses cannot be derived from their own immediate senses but must be derived from the immediate senses of other states, either other states of the same subject or other states of other subjects (as on Kriegel's (2011) view). Option (2), however, is not compatible with my view of reflective senses described above, since my view requires that a representation with a reflective sense have an immediate sense that can partake in experiences of cashing out.

For the PIT approach, option (3), on which nonconscious occurrent states neither phenomenally nor derivatively represent their alleged contents, results in the view that nonconscious occurrent states lack both immediate and reflective senses. Of course, they might still have various neural and functional properties, and they might still track various worldly items. In virtue of these features, we might even say that they represent, perhaps in a loose or extended sense of "represent," one that does not amount to their having immediate or reflective senses.

Option (3) is arguably the least extreme of the three options. It is very much in line with what we might consider to be the standard view of nonconscious 
occurrent states: It accepts that such states lack phenomenal characters, that they have neural and functional properties, that they track various items, and even that they "represent," insofar as representation is merely a matter of their neural, functional, or tracking features. The main potential disagreement between option (3) and the standard view is presumably over whether the nonconscious "representation" it allows for amounts to the having of immediate or reflective senses or whether phenomenal properties are required. In other words, the main disagreement is over whether the PIT approach itself is true of phenomenally conscious intentional states - which is something I've already argued for. So, rather than being the most extreme of the three options, the third option arguably represents the smallest reasonable departure from what we might take to be the standard view.

Which of the three options the PIT approach should adopt depends in part on whether there is independent reason to ascribe immediate or reflective senses to nonconscious occurrent states. My preferred view is a combination of (1) and (3) on which some nonconscious occurrent states have phenomenal contents, and hence immediate and perhaps reflective senses, while others have neither phenomenal nor derived contents, and hence neither immediate nor reflective senses. For example, high-level states involved in nonconscious problem solving might have immediate senses we are not consciously aware of, while states in early visual processing might have neither immediate nor reflective senses. ${ }^{21}$

\section{Conclusion}

I have argued that there are immediate and reflective senses and that the two senses come apart in almost all cases of thought and in many cases of perceptual

\footnotetext{
${ }^{21}$ For more details, see Mendelovici 2018: §8.4. Note that there "nonconscious states" is used to pick out mental states that are not phenomenally conscious, while here it is used to pick out mental states that we are not consciously aware of.
} 
representation. I explored various ways we might try to account for immediate and reflective senses and suggested that the most promising way is the PIT approach.

One way to put the view of immediate and reflective senses that I've proposed is this: Representations have immediate senses, which are phenomenal contents. Some representations, in addition to having immediate senses, are treated as if they stood for the immediate senses of other representations, which is, roughly, a matter of having dispositions to accept the immediate senses of those other representations as equivalent to or further elucidations of their immediate senses. When we treat a representation as if it stood for the immediate senses of other representations, those other representations' immediate senses are its reflective sense. The end result is a picture on which thoughts and other representational states provide us two perspectives on the world, an immediate one, one that is running through our minds, and a derived one, one that is available upon reflection. ${ }^{22}$

\section{References}

Bayne, T. and Montague, M. (2011). Cognitive Phenomenology. Oxford University Press, USA.

Block, N. (1986). Advertisement for a semantics for psychology. Midwest Studies in Philosophy, 10(1):615-78.

Bourget, D. (2010a). Consciousness is underived intentionality. Noûs, 44(1):3258.

\footnotetext{
${ }^{22}$ Many thanks to David Bourget for helpful comments on earlier drafts and to audiences at Oakland University's philosophy department, Victoria University at Wellington philosophy department, and PhilMiLCog 2014 at the University of Western Ontario for helpful discussion.
} 
Bourget, D. (2010b). The Representational Theory of Consciousness. PhD thesis, Australian National University.

Bourget, D. (2017). The role of consciousness in grasping and understanding. Philosophy and Phenomenological Research, 95(2):285-318.

Bourget, D. and Mendelovici, A. (2016). Phenomenal intentionality. In Zalta, E. N., editor, The Stanford Encyclopedia of Philosophy. Metaphysics Research Lab, Stanford University.

Brooks, L. R. (1978). Nonanalytic concept formation and memory for instances. In Rosch, E. and Lloyd, B. B., editors, Cognition and concepts, pages 169-211. Hillsdale, NJ: Erlbaum.

Carey, S. E. (1985). Conceptual change in childhood. MIT Press, Cambridge, MA.

Chalmers, D. J. (2016). The combination problem for panpsychism. In Jaskolla, L. and Bruntrup, G., editors, Panpsychism, pages 179-214. Oxford University Press.

Dretske, F. (1995). Naturalizing the Mind. MIT Press, Cambridge.

Farkas, K. (2008). Phenomenal intentionality without compromise. The Monist, 91(2):273-293.

Fodor, J. A. (1975). The Language of Thought. Harvard University Press, Cambridge, MA.

Fodor, J. A. (1987). Psychosemantics. MIT Press, Cambridge.

Frege, G. (1892/1948). Sense and reference. The philosophical review, 57(3):209230 . 
Gopnik, A. and Wellman, H. M. (1994). The theory theory. In Hirschfeld, L. A. and Gelman, S. A., editors, Mapping the mind: Domain specificity in cognition and culture, pages 257-293. Cambridge University Press, Cambridge.

Harman, G. (1987). (Non-solipsistic) conceptual role semantics. In LePore, E., editor, New Directions in Semantics, pages 55-81. Academic Press, London.

Horgan, T. and Graham, G. (2009). Phenomenal intentionality and content determinacy. In Schantz, R., editor, Prospects for Meaning. De Gruyter, Amsterdam.

Horgan, T. and Tienson, J. (2002). The intentionality of phenomenology and the phenomenology of intentionality. In Chalmers, D. J., editor, Philosophy of Mind: Classical and Contemporary Readings, pages 520-533. Oxford University Press, Oxford.

Kriegel, U. (2011). The Sources of Intentionality. Oxford University Press.

Loar, B. (2003). Phenomenal intentionality as the basis of mental content. Reflections and Replies: Essays on the Philosophy of Tyler Burge.

Medin, D. L. and Schaffer, M. M. (1978). Context theory of classification learning. Psychological Review, 85:207-238.

Mendelovici, A. (2010). Mental Representation and Closely Conflated Topics. $\mathrm{PhD}$ thesis, Princeton University.

Mendelovici, A. (2013). Reliable misrepresentation and tracking theories of mental representation. Philosophical Studies, 165(2):421-443.

Mendelovici, A. (2016). Why tracking theories should allow for clean cases of reliable misrepresentation. Disputatio, 8(42):57-92. 
Mendelovici, A. (2018). The Phenomenal Basis of Intentionality. Oxford University Press.

Mendelovici, A. (2019). Panpsychism's combination problem is a problem for everyone. In Seager, W., editor, Handbook of Panpsychism. Routledge.

Mendelovici, A. and Bourget, D. (2014). Naturalizing intentionality: Tracking theories versus phenomenal intentionality theories. Philosophy Compass.

Mendelovici, A. and Bourget, D. (forthcoming). Consciousness and intentionality. In Kriegel, U., editor, Oxford Handbook of the Philosophy of Consciousness. Oxford University Press.

Millikan, R. G. (1984). Language, Thought and Other Biological Categories. MIT Press, Cambridge, MA.

Murphy, G. L. (2004). The Big Book of Concepts. MIT Bradford, Cambridge.

Murphy, G. L. and Medin, D. L. (1985). The role of theories in conceptual coherence. Psychological Review, 92:289-316.

Nagel, T. (1974). What is it like to be a bat? The Philosophical Review, $83(4): 435-450$.

Neander, K. (2017). A Mark of the Mental: A Defence of Informational Teleosemantics. Cambridge, USA: MIT Press.

Pitt, D. (2004). The phenomenology of cognition or what is it like to think that P? Philosophy and Phenomenological Research, 69(1):1-36.

Pitt, D. (MS-). The quality of thought, chapter Unconscious thought.

Prinz, J. (2002). Furnishing the Mind: Concepts and their Perceptual Basis. MIT Bradford, Cambridge, MA. 
Roelofs, L. (2014). Phenomenal blending and the palette problem. Thought: A Journal of Philosophy, 3(1):59-70.

Rosch, E. (1975). Cognitive representations of semantic categories. Journal of Experimental Psychology: General, 104(3):192-233.

Rosch, E. and Mervis, C. (1975). Family resemblances: Studies in the internal structure of categories. Cognitive Psychology, 7(4):573-605.

Searle, J. (1990). Consciousness, explanatory inversion and cognitive science. Behavioral and Brain Sciences, 13:585-642.

Siegel, S. (2005). Which properties are represented in perception? In Szabo Gendler, T. and Hawthorne, J., editors, Perceptual Experience. Oxford University Press, Oxford.

Siewert, C. (1998). The Significance of Consciousness. Princeton University Press, Princeton.

Stampe, D. W. (1977). Towards a causal theory of linguistic representation. Midwest Studies in Philosophy, 2(1):42-63.

Strawson, G. (1994). Mental Reality. MIT Press, Cambridge. 